\title{
Study on Development Policies of the Special Industries in Ethnic
}

\author{
Minority Areas of China \\ Jingfu Guo, Jingtao Wang and Jianbin Wang \\ School of Economy \& Management, Dalian Nationalities University \\ Dalian 116600, China \\ E-mail: drguo@dlnu.edu.cn
}

This paper is sponsored by Liaoning Social Science Planning Program (L09BJL014)

\begin{abstract}
The special industries are based on special resources with distinctive regional characteristics, including rarity, ecological and sustainable development, and the special product system to meet the market demand. To gain a competitive advantage in the market today, ethnic minority areas should nurture and develop these special industries. Based on the analysis of examples and the features of these industries, this study proposes a set of development policies, such as being market-oriented, making use of the special resources and regional advantages, building a recycling economy model, and developing the green industries and nurture the ethnic culture related industries, etc.
\end{abstract}

Keywords: Special industry, Recycling economy, Green industry, Cultural industry

\section{Introduction}

The formation and development of an ethnic minority is closely related to its economy. Economic development forms a basis for prosperity. China's ethnic minority areas (referring to China's five minority autonomous regions, as well as Yunnan, Guizhou and Qinghai provinces with large ethnic minorities populations) are located mostly in remote areas with poor infrastructure. The poor infrastructure and a number of historical factors cause widespread poverty. Therefore, it is critical to boost the economic development in these areas and narrow the development gap. This is a starting point for minority policies and the key to solving current problems and issues in these minority areas.

Geographical regions where ethnic minority live, contributes to the world more uniquely. Upgrading and optimizing the industrial structure is the most direct and significant way to develop regional economy. A well-designed industrial structure is a necessary condition for sustainable development. As people shift from survival consumption to a quality-of-life consumption, ethnic minority areas have to develop the special industries to gain competitive advantages. The special industries are based on special resources with distinctive regional characteristics, rarity, ecological and sustainable development, and the special product system to meet the market demand (Wang 2004). Under the conditions of a market economy, regional economic development should follow the principle of differentiated and comparative advantage, allocating resources based on the market and establishing competitive advantages with regional economic characteristics. Special industries are special resource-based, the characteristics of these products are at the core of such an industrial system. Characteristics of China's ethnic areas show broad market prospects. For example, Xinjiang geography and tropical warm climate create unique conditions for products like cotton, fruits, livestock and other species with superior quality; Yunnan's tobacco, rubber, spices, coffee, tropical fruits, etc. are very unique products; Tibet's light and heat resources make its drugs and yak very special; Qinghai plateau's animal and plant resources are also very unique. The rise of tourism for new and special resources in the ethnic areas has enabled the special industries to become their pillar industries.

This study describes the special industry content and features by using the case study method and related theory. It explores the development policies for ethnic areas and provides guidance for achieving competitive advantages and sustainable economic development.

\section{Special Industry Content and Features}

Special industries are based on special resources and products. They rely on modern technology with a market-oriented approach and focus on the comprehensive development of the formation of a distinct regional, irreplaceable, sustainable and competitive product system to meet the public needs and wants (Guo, 2006). The "special" aspects of the special 
products and services are embodied in the differentiated customer values that are irreplaceable and meet the special needs of consumers.

\subsection{Regional Characteristics}

Special industries rely on the unique characteristics of the people, the natural geographical climate, and the cultural resources. They are all closely related. These characteristics determine the uniqueness of the special industries. In other words, people in the regional areas need to take advantage of these attributes in order to develop the special industries. The regional characteristics of the special industries are always dependent on the geographical space, whose different resource elements and region configurations contribute to the overall economic structure. The regional difference based on natural regional characteristics, can be used as the basis for developing special industries.

\subsection{Market Adaptability}

Market changes drive the industrial structure changes. Regional economic development must be market oriented. Market demand determines the adjustment of the industrial structure. Whether an industry can be developed and how large its scale of development is depend on market needs, wants, and the size and potential of the market itself. The special industries are different from other industries because they provide unique products and services and are able to adapt to meet the special needs of the market. Therefore, the unique value of products and services forms the core of the special industries.

\subsection{Rarity}

The survival and development of a special industry depend on its uniqueness and its difficulty of being copied. The significance of its scarcity comes from the nature of the resource scarcity and our insight and ability to seize the development opportunity. Both of these characteristics are critical because the resource is scarce and the opportunity could be gone at any moment.

\subsection{Sustainability}

Ecological civilization requires human activity and the natural environment to be in harmony. To achieve this purpose, it is necessary to establish a scientific outlook on development, coordination of nature, green consumption, and ecological sustainable development to ensure sustainable economic development. The reason to develop special industries is to promote economic development and resource efficient utilization. Therefore, while considering the economic development and benefits, close attention should be given to the social and ecological environment so that the special industries will continue to stay on the path of sustainable development.

\section{Development Policies for the Special Industries in the Ethnic Minority Areas}

The core of a special industry is its unique products and services. There must be a compatible match between the regional characteristics and the special industry in order for the development to be realized. To be competitive the special industries must have influence and be supportive of the local economic development. They must display strong presence in the market and become a leader in order to help other related industries achieve a sustainable development.

\subsection{Market Orientation}

The nature of the market economy is based on the relationship between "supply and demand." The market demand is the direct driving force for industrial development. Market orientation is used to develop the right products and services to meet the needs and wants of both international and domestic customers. Special Industries should strive for the development of excellent and innovative new products and gain a greater market share. Chinese wolfberry from Ningxia Hui Autonomous Region is an internationally recognized product brand name. The upper reaches of the Yellow River are the best place to grow Chinese wolfberry. In addition, the upper reaches of the Yellow River are the world's birthplace of artificial cultivation for Chinese wolfberry. With the growing demand for medical products, health products, and Islamic foods made from Chinese wolfberries, developing Chinese wolfberry products from Ningxia has become the most valuable special industry with growing developmental prospects.

The medicine and health products with special effectiveness made from Chinese wolfberry, including Lycium barbarum polysaccharides, wolfberry seed oil and other products are very competitive in the market and maintain a strong competitive advantage.

\subsection{Based on Special Resources}

Resources are a prerequisite for human economic activities. Resources provide the basis and environment for human survival and economic development. Ethnic minority areas are not only a wealth of ecological resources, but also have abundant natural resources, particularly energy and mineral. These resources objectively constitute an advantage and provide a good economic base for sustainable development. The spatial distribution of natural resources is non-equilibrium, region specific, and exclusive, especially for the special products and services. The features contribute significantly to the formation of the characteristics of the special industries. It has a distinctiveness and "personality" 
which is difficult to be duplicated, migrated, or replaced by the relationship of market supply and demand. The cultivation and development of special industries in the ethnic minority areas are shown in the following chart:

$<$ Inser Figure 1 here $>$

For example, taking the advantage of local, natural, and cultural resources, Lhasa, Tibet develops special tourism. There are more than 100 tourism sites in the Lhasa area, four of which are among the best in the nation (national 4A-class). There are the majestic Himalayan Mountains with their majestic glaciers, the beautiful tranquil grasslands, the boundless expanses of sparkling lakes including that of the Namu Highlands Lake and the spectacular Yangbajing Geothermal (it is called "geothermal Museum"), as well as the large-scale and intricately styled temples towering in Jinding such as Potala Palace, Jokhang Temple, and the Drepung Monastery. Also, contributing to the grandeur of this area are the fantastic murals, statue art of Tangga, the ancient sites of the lasting tribute Qu Gong, the Zhala road caves, and the unique charm of Tibetan songs, dance, and opera. These are just some of the colorful customs of the minority people. All these features make Lhasa an integrated tourist destination. The natural scenery and its beautiful, picturesque, scenic, vivid landscape make it an irreplaceable location for the process of communicating and promoting Tibetan culture.

\subsection{Expand Exchanges with Foreign Countries}

British classical economist David Ricardo once confirmed his Comparative Advantage Ttheory through the analysis of two countries with different endowments in their production elements, asserting that as long as the countries have comparative advantages, they will benefit from international trade. China has 22,000 kilometers of land that border foreign countries, including 19,000 kilometers in the minority territories where 107 of 135 border counties are ethnic minorities. The special frontier locations of the minority areas have a unique advantage in today's global economy. Xinjiang Uygur Autonomous Region, is located in the Asia-Europe abdomen with the longest border in China's provinces and autonomous regions. The South-West Asian economic bloc is the fourth largest one after the North American economic bloc, the EU economic bloc, and the East Asian economic bloc. At present, Xinjiang has become a major port along the border with 17 national first-class ports and 12 second-class ports. Adhering to the principle of "keeping the East-West channel open and smooth", they strive to create an environment to nurture, promote, secure, and benefit business activities in Xinjiang. In fact, through economic and trade cooperation and coordination with neighboring countries, Xinjiang achieved $\$ 17.6$ billion in border trade in 2008 . This accounts for $57 \%$ of total border trade, making Xinjiang the largest border trader in China.

\subsection{Extend the Industrial Chain and Upgrade High Value-Added Products}

Many industries in minority areas are still in the early development stages and lack the backbone of an enterprise. The industrial chain is shorter and most products are low in value. The driving force of special industries in the economy as a whole is not strong. Efforts should be made to extend the industrial chain and build leading industries to improve the capability of R\&D and advanced engineering in the special industries. This is so they can provide high value-added products and turn their resource advantages into competitive advantages in the market.

\subsection{Based on "Recycling Economy" Model for Industrial Development}

The "Recycling economy" model of development is consistent with the nature of the ecological civilization. Its core basis entails the efficient use of resources and recycling. "Reduction-Reuse-Recycling" is the principle for economic development. To achieve the goal of "green minority areas" and "eco-industry", efforts should be made to apply the "recycling economy" model in the development of special industries, achieving harmonious and sustainable economic development for the whole society. Another example, Golmud City in Qinghai Province, is located in the Qaidam Basin which was listed as one of thirteen (industrial parks) circular economy pilot projects of the country in October 2005. It already has "oil and gas - salt chemical", "coal - coke - salt chemical", "Coal Chemical Industry - salt chemical industry - building materials", "non-ferrous metals - natural gas - salt chemical", and "iron ore - coke - steel" five recycling industry chains. All kinds of resources in the park are recycled. Golmud City has vast geographical areas and unique natural conditions. The annual average sunshine time is more than 3300 hours. Its solar radiation is the most abundant in the world. In June 2009, with 200,000 kilowatts of photovoltaic grid power, the plant project started in the city of Golmud in Qinghai, which will become the core of solar energy gathering area. Solar energy will become the next round pillar industry of the Qaidam Basin allowing for another cycle of economic development.

\subsection{Develop Green Industry and Nurture the Culture Industry}

The green industry is also referred to as the eco-industry. In the production process, it uses resources efficiently and does not damage the ecological balance. It does not pollute the environment, provides quality products to meet the people's health needs, and at the same time maintains the original ecological needs. China's ethnic minority areas should enhance the value of resources and market efficiency through research and development on their rich variety of natural resources. Therefore, the green industries with ecological characteristics will be enhanced within the ethnic minorities. The Inner Mongolia Autonomous Region is another example. It has unique advantages in resources for developing the 
green food industry. The region has 130 million mu of grassland, accounting for $1 / 5$ of the nation. On the theme, "Half of a brand is the culture", the green grassland culture nurtured the green food brand. Inner Mongolia has established more than twenty successful grassland brands that are influential and have become leading enterprises, such as Yili Group, grassland Hing Fat Group, Mengniu, and Ningcheng Laojiao Group etc. In Inner Mongolia, people often use the metaphor of eating "Prairie Xingfa" and "Small Fat Lamb" food, drinking "Yili" and "Mengniu" milk and "Hetao" and "Mongolian King" liquor, and wearing "Ordos" and "Deer King" clothes.

In the 90's of last century, former U.S. President Bill Clinton put forward a Culture Industry concept. Cultural industry provides the public with cultural entertainment products and services that protect cultural relics and heritage. It is derived from the individual creativity, skill, talent, development, and application of intellectual property rights. The culture industry creates wealth and employment and is recognized as an era of global economic integration or the "sunrise industry" of the 21st century. It is the right time to make use of the advantages of minority cultural resources and encourage ethnic minorities to diversify the cultural industries. For example, "Yunnan Impression" is an integrated large-scale show with Yunnan folk songs and dances. In this show seventy percent of the performers were from the villages of Yunnan's ethnic minority. The clothes and accessories they wore on the stage consist of their every day attire in real life. The famous dancer Yang Liping, the "God of Dance", was the director and leading performer of the show. There were authentic props, apparel, and the singing was not cut down and polished. Instead it contained original and imaginative dance, traditional songs and dances, and cutting-edge modern dance, which was perfectly integrated into the show. It literally "re-created" and showed the fabulous rich ethnic customs in Yunnan. No wonder it won the gold medal at the fourth "Lotus Award" Dance Festival of China. Experts called it the "Enlightenment of Minority Folk Dance" and the audience enjoyed the power of art.

\section{Conclusion}

China's government proposes "build ecological civilization, adjust industrial structure, keep economic growth, and construct harmonious society." As the frontier border of the country with a green screen, the ethnic minority areas have the advantages of geographic and ecological resources, cultural diversity, and political autonomy. They should turn these advantages into real economic ones, promote the natural ecological environment, nurture the ethnic culture and inheritance, and achieve the goal of sustainable development and social progress.

\section{References}

Baoli Bai. (2007). A study on the ecological ethics of the Chinese minorities (D), Beijing: Dissertation of the Central University of the Minorities, 3.

Guo, Jingfu. (2006). On the special industries in ethnic minority areas. Beijing: National Press.

Hellstrand, S. (2006). A multi-criteria analysis of sustainability effects of increasing concentrate intensity in Swedish milk production 1989-1999. Environment, Development and Sustainability, 8(3), 351-373.

$\mathrm{Hu}$, Jing and $\mathrm{Gu}$, Jiang. (2007). China's culture industry development strategy and the path choice. Economic Management, (21), 62-65.

Chen, Jiancheng. (2008). A study on the ecological civilization and the continuous development of the Chinese forest industry. Chinese hunan resources and the environment, 4, 139-142.

Chen, Jiancheng. (2008). A study on the ecological civilization and the continuous development of the Chinese forest industry. Chinese hunan resources and the environment, 4, 139-142.

Wang, Fang. (2004). Analysis of the special economy. Gansu Social Science, (2), 127-129.

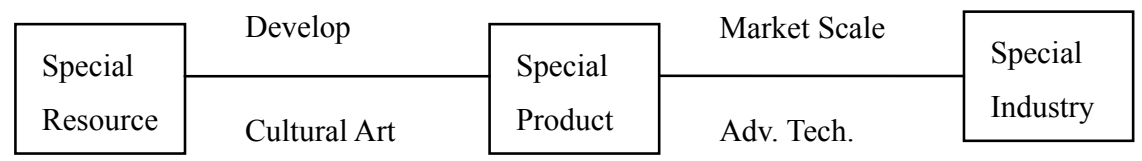

Figure 1. Process of Special Industry. 